\title{
Effects of acclimation on the haematological indices of different groups of fresh water teleosts
}

\author{
K. Roy George*, N. A. Malini and D. Rajasree
}

Post Graduate and Research Department of Zoology, St. Thomas College Kozhencherry - 689641 (Kerala), INDIA

*Corresponding author: E- mail: dr.roygeorgek@gmail.com

Received: September 7, 2013; Revised received: October 18, 2014; Accepted: January 26, 2015

\begin{abstract}
Hematological parameters have been recognized as valuable tools for monitoring fish health. The aim of the present study was to obtain a basic knowledge of the hematological responses of different groups of fresh water teleosts during acclimation period. Haematological analysis was carried out in three different groups of teleosts namely Group I: Heteropneustes fossilis and Clarias gariepinus (Siluriformes), Group II: Anabas testudineus and Channa striatus (Perciformes), Group III: Labeo rohita and Cyprinus carpio (Cypriniformes). In all groups of teleosts, $\mathrm{RBC}$ and $\mathrm{Hb}$ were significantly $(\mathrm{p}<0.05)$ decreased after 7 days of captivity in response to stress factors raised in capture, handling and sampling procedure. WBC was found to be significantly $(p<0.05)$ increased in group I (Siluriformes), group II (Perciformes) and group III (Cypriniformes) of teleosts after 7 days of captivity due to enhanced production of leucocytes in the hematopoietic tissue of the kidney and the spleen. RBC count and WBC count were found to be higher in $H$. fossilis and $C$. gariepinus than other groups of teleosts due to their active predacious nature. $\mathrm{Hb}$ values were high in $2^{\text {nd }}$ group (Perciformes) consisting of $A$. testudineus and $C$. striatus by virtue of their possessions of accessory respiratory organs. PCV, MCV and MCHC were significantly $(p<0.05)$ increased in three groups of teleosts during acclimation and values were high in second group of consisting of $A$. testudineus and $C$. striatus. $\mathrm{MCH}$ was higher in $3^{\text {rd }}$ group of fishes consisting of $L$. rohita and $C$. carpio.
\end{abstract}

Keywords: Acclimation, Captivity, Haematology, Haematocrit, Haemoglobin, Teleost fish

\section{INTRODUCTION}

Haematological indices are important parameters for the evaluation of fish physiological status. Their changes depend on the fish species, age, the cycle of sexual maturity and health condition (Vosylien'e, 1999; Hrubec et al., 2001). It has been observed that blood parameters such as haematocrit, hemoglobin concentration and $\mathrm{RBC}$ count are related to environmental factors such as water temperature and salinity (Graham, 1997). Additionally, the relationship between $\mathrm{Hb}$ and $\mathrm{O}^{2}$ differs between loading and unloading sites and shows adaptations not only to environmental conditions but also to metabolic requirements, both of which govern oxygen availability and transport to tissues (Weber and Wells, 1989). Such adaptations may involve quantitative changes in total $\mathrm{Hb}$ content, or qualitative changes in $\mathrm{Hb}-$ oxygen - binding properties, and may appear both at the inter and intra-specific level (Weber and Wells, 1989). The hematological tests can also provide important information on erythropoiesis condition (Rehulka and Adamec, 2004). The values of the haematocrit, hemoglobin concentration and mean cell hemoglobin concentration indicate the blood oxygen-carrying capacity in the case of teleost fish. These primary red blood cells indices may be highly variable and dependent on the fish species. The hemoglobin rate needed to reversibly bind oxygen reflects the ability to extract oxygen from water and also the need for delivering oxygen to the tissue. Consequently, fish differ considerably in their activity patterns accordingly to their habits (Graham et al., 1985; Wells et al., 2005). Therefore, besides serving as an index of oxygen transport capability; the hematological parameters may also supply additional information about the health of a fish population and its immune system. These indices have been employed in effectively monitoring the responses of fishes to the stressors and thus their health status under such adverse conditions. They can provide substantial diagnostic information once reference values are established under standardized conditions. Therefore, in the present study changes in the hematological characteristics of different groups of teleosts at normal and laboratory conditions were studied. The fish species selected for the present study were Heteropneustes fossilis and Clarias gariepinus (siluriformes) - Group I ; Anabas testudineus and Channa striatus (perciformes) - Group II ; Labeo rohita and Cyprinus carpio (cypriniformes) - Group III.

\section{MATERIALS AND METHODS}

20 live, healthy animals of each species (irrespective of sex and almost equal size) were collected from paddy fields and brought to the laboratory. The fishes 
were treated with $0.05 \% \mathrm{KMnO}_{4}$ solution for 2 min to clear any external infection. They were then transferred to $100 \mathrm{~L}$ capacity glass tanks filled with dechlorinated water. A minimum of 4 fishes were introduced in each tank. The carnivorous fishes were fed with natural food like Tilapia fingerlings, insects, earthworm etc. and cultivable fishes with ground nut oil cake, rice bran etc. The water was renewed after every $24 \mathrm{~h}$, leaving no fecal matter, unconsumed food or dead fish, if any. Every effort was made to provide healthy condition for fish and no mortality occurred during this period. The physicochemical characteristics of the tap water used in this study were: Temperature $-24 \pm 2{ }^{0} \mathrm{C}$, pH-7,Dissolved $\mathrm{O}_{2}-4.48 \pm 1.6 \mathrm{ml} / 1$, Alkalinity - $35 \pm 2$ ppm, $\mathrm{CO}_{2}-8 \pm 2 \mathrm{ppm}$.

At the start of experiment i.e. at the day of catch itself, one half of the experimental fishes was sacrificed and their blood samples were collected using syringe and needle by puncturing the caudal peduncle to cut ventral aorta. Blood was collected in small glass bottles containing a pinch of sodium citrate as an anticoagulant. This fresh unclotted blood was used for studying hematological parameters. The blood parameters selected for the present study were red blood cell count (RBC), white blood cell count (WBC), hemoglobin $(\mathrm{Hb})$, packed cell volume $(\mathrm{PCV})$ or haematocrit, mean corpuscular volume (MCV), mean corpuscular hemoglobin $(\mathrm{MCH})$ and mean corpuscular hemoglobin constant (MCHC). The other halves of the fish were analyzed for these parameters similarly by the end of the $7^{\text {th }}$ day.

Erythrocyte constants were determined as described by Cyril and Eric (1979). RBC count and WBC count were done using the Neubauer haemocytometer. The hemoglobin concentration was estimated by Sahli's method. A minimum of 8 replicates were taken for each parameter and the data was subjected to statistical analysis using ANOVA and student' $t$ ' test.

\section{RESULTS}

Table 1. represents changes in haematological parameters between 3 groups of fishes in normal and acclimation period. The ' $\mathrm{t}$ ' test was done by categorizing the fishes into 3 groups belonging to three orders. Then the inter group comparisons were done from the values of first day and $7^{\text {th }}$ day at $\mathrm{P}_{05}$ significance. The haematological changes produced by the effects of acclimation to laboratory condition showed a significant $(\mathrm{p}<0.05)$ reduction in the values of $\mathrm{RBC}$ and $\mathrm{Hb}$ in three groups of fish species. $\mathrm{RBC}$ count and WBC count at normal and laboratory conditions were found to be higher in siluriformes (H. fossilis and C. gariepinus) when compared to other groups. The WBC count and PCV were significantly $(p<0.05)$ increased in three groups after acclimation to laboratory condition. $\mathrm{MCV}$ and $\mathrm{MCH}$ were also significantly $(p<0.05)$ increased in three groups in acclimation period. However, MCHC was significantly $(p<0.05)$ decreased in three groups in laboratory condition.
Perciformes possess highest value of $\mathrm{Hb}, \mathrm{PCV}, \mathrm{MCV}$ and $\mathrm{MCHC}$ in normal condition and in the acclimation period. On the contrary, $\mathrm{MCH}$ was higher in cypriniformes in normal and acclimation period.

\section{DISCUSSION}

Hematological variables have been used as indices of fish health status in a number of fish species to detect physiological changes as a result of stress condition such as exposure to pollutants, hypoxia, transportation, anesthetic and acclimation (Akinrotimi et al., 2009). Hematological indices are ready tools used by fish biologists and researchers in many parts of the world. The blood constituents in teleost fishes are influenced by factors like temperature ecological habitat, food selection and mode of life. Therefore, it is difficult to establish any normal values for the class as a whole. But, if data are collected for different species as well as within species under different conditions, some normal ranges of values can be arrived at, which can form a valuable diagnostic aid in fisheries (Goel et $a l ., 1984)$. In the present study altered hematological profile of different groups of teleosts at normal and laboratory conditions were studied.

In our study, $\mathrm{RBC}$ and $\mathrm{Hb}$ in different groups of teleosts were decresed after 7 days in response to certain stress factors due to capture, handling and sampling procedures which can cause intra-species hematological variations (Hattingh and Van Pletzen, 1974). The reduction observed in these parameters is an indication of acclimation to the laboratory conditions. This response could be as a result of disruption in erythrocyte production (Wintrobe, 1978; Omoregie, 1995), haemodilution (Sampath et al., 1993) and destruction of intestinal cells involved in the production of vitamin $B_{12}$ used in the production of the hemoglobin portion of the red cells (Gardner and Yevich, 1970). Similar results were recorded by Gabriel et al. (2007a) in Sarotherodon melanotheron subjected to acclimation for seven days. In a stress situation erythrocyte count is one of the first parameters that is affected. The decrease in RBC count in various teleosts can be attributed to scarcity of food in the laboratory conditions. The competition for food causes a stress on the individuals which decreases their red blood cell count and induces anemia (Verma et al., 1982).

Das (1965) stated that both RBC and Hb concentration tend to increase with length and age. Banerjee (1957) reported that both of them increase in fish with increase in their weight, which have been established in our study in first group of teleosts consisting of $H$. fossilis and $C$. graiepinus. Since both of them are carnivore, their metabolic rate is high and consumes high levels of proteins which are utilized for energy. When compared to herbivorous cultivable fishes, their respiratory rate and oxygen consumption are very high; thus the fish requires increased surface area for 
Table 1. The ' $t$ ' test of haematological parameters of 3 groups of fishes in normal and acclimation period.

\begin{tabular}{|c|c|c|c|c|c|c|}
\hline \multirow[t]{2}{*}{ Parameter } & \multicolumn{2}{|c|}{ Siluriformes (Group I) } & \multicolumn{2}{|c|}{ Perciformes (Group I) } & \multicolumn{2}{|c|}{ Cypriniformes (Group III) } \\
\hline & Day 1 & Day 7 & Day 1 & Day 7 & Day 1 & Day 7 \\
\hline $\begin{array}{l}\text { RBC count } \\
\left(10^{6} \mathrm{~mm}^{3}\right)\end{array}$ & $3.89 \pm 0.11$ & $* 2.46 \pm 0.13$ & $3.41 \pm 0.30$ & $* 2.02 \pm 0.09$ & $3.29 \pm 0.18$ & $* 2.19 \pm 0.13$ \\
\hline $\begin{array}{l}\text { WBC Count } \\
\left(10^{5} \mathrm{~mm}^{3}\right)\end{array}$ & $3.97 \pm 0.12$ & $* 5.20 \pm 0.09$ & $3.82 \pm 0.07$ & $* 4.98 \pm 0.16$ & $3.90 \pm 0.08$ & $* 4.81 \pm 0.13$ \\
\hline $\mathrm{Hb}(\mathrm{g} \%)$ & $13.95 \pm 0.2$ & $* 12.33 \pm 0.2$ & $16.67 \pm 0.6$ & $* 14.20 \pm 0.4$ & $12.9 \pm 0.2$ & $* 11.04 \pm 0.3$ \\
\hline PCV $(\%)$ & $29.7 \pm 0.8$ & $* 34.3 \pm 0.4$ & $42.07 \pm 2.26$ & $* 57.4 \pm 1.97$ & $29.8 \pm 1.3$ & $* 35.8 \pm 0.4$ \\
\hline MCV (fL) & $76.2 \pm 1.2$ & $* 140.7 \pm 6.5$ & $131.6 \pm 11.4$ & $* 269.3 \pm 19.5$ & $93.0 \pm 9.6$ & $* 179.9 \pm 9.2$ \\
\hline $\mathrm{MCH}(\mathrm{Pg})$ & $42.9 \pm 1.7$ & $* 55.5 \pm 3.1$ & $39.9 \pm 3.3$ & $* 58.13 \pm 4.8$ & $43.14 \pm 1.9$ & $* 58.2 \pm 3.0$ \\
\hline $\mathrm{MCHC}$ & $33.9 \pm 2.08$ & $* 21.6 \pm 0.81$ & $56.4 \pm 2.4$ & $* 41.4 \pm 1.06$ & $44.2 \pm 2.3$ & $* 30.8 \pm 0.54$ \\
\hline
\end{tabular}

*significant $(\mathrm{p}<0.05)$

Table 2. Summary of analysis of variance (two factor) of the data on haematological parameters of fresh water teleosts (between groups and between days).

\begin{tabular}{llcccccc}
\hline Parameter & Source of Variation & SS & df & MS & F & P-value & F crit \\
\hline RBC & Sample(b/w groups) & 2.16 & 2 & 1.07 & $* 4.51$ & 0.016694 & 3.219942 \\
& Columns(b/w days) & 20.52 & 1 & 20.52 & $* 85.88$ & $1.03 \mathrm{E}-11$ & 4.072654 \\
& Interaction & 0.27 & 2 & 0.13 & 0.56 & 0.573329 & 3.219942 \\
WBC & Sample(b/w groups) & 0.21 & 2 & 0.10 & 0.96 & 0.390201 & 3.219942 \\
& Columns(b/w days) & 14.64 & 1 & 14.64 & $* 133.48$ & $1.27 \mathrm{E}-14$ & 4.072654 \\
& Interaction & 0.50 & 2 & 0.25 & 2.29 & 0.112769 & 3.219942 \\
$\mathrm{Hb}$ & Sample(b/w groups) & 97.38 & 2 & 48.69 & $* 49.19$ & $9.85 \mathrm{E}-12$ & 3.219942 \\
& Columns(b/w days) & 48.28 & 1 & 48.28 & $* 48.78$ & $1.53 \mathrm{E}-08$ & 4.072654 \\
& Interaction & 1.44 & 2 & 0.72 & 0.72 & 0.488296 & 3.219942 \\
PCV & Sample(b/w groups) & 3213.72 & 2 & 1606.86 & $* 103.88$ & $5.5 \mathrm{E}-17$ & 3.219942 \\
& Columns(b/w days) & 899.51 & 1 & 899.51 & $* 58.15$ & $1.88 \mathrm{E}-09$ & 4.072654 \\
& Interaction & 268.66 & 2 & 134.33 & $* 8.68$ & 0.000698 & 3.219942 \\
$\mathrm{MCV}$ & Sample(b/w groups) & 71170.32 & 2 & 35585.16 & $* 36.38$ & $6.79 \mathrm{E}-10$ & 3.219942 \\
& Columns(b/w days) & 111300.65 & 1 & 111300.65 & $* 113.79$ & $1.57 \mathrm{E}-13$ & 4.072654 \\
& Interaction & 11259.08 & 2 & 5629.54 & $* 5.75$ & 0.006177 & 3.219942 \\
$\mathrm{MCH}$ & Sample(b/w groups) & 87.61 & 2 & 43.80 & 0.55 & 0.578552 & 3.219942 \\
& Columns(b/w days) & 2800.82 & 1 & 2800.82 & $* 35.44$ & $4.63 \mathrm{E}-07$ & 4.072654 \\
& Interaction & 0.63 & 2 & 0.31 & 0.00400 & 0.996004 & 3.219942 \\
$\mathrm{MCHC}$ & Sample(b/w groups) & 3586.58 & 2 & 1793.29 & $* 76.25$ & $1.05 \mathrm{E}-14$ & 3.219942 \\
& Columns(b/w days) & 2208.99 & 1 & 2208.99 & $* 93.93$ & $2.83 \mathrm{E}-12$ & 4.072654 \\
& Interaction & 15.20 & 2 & 7.60 & 0.32 & 0.72558 & 3.219942 \\
\hline \multirow{3}{*}{$\mathrm{s}$} & & & & & &
\end{tabular}

*significant $(\mathrm{p}<0.05)$

respiration. So $\mathrm{RBC}$ was found to be higher in this group of fishes compared to other teleosts. Goel et al., (1984) reported that the RBC numbers are found higher in the active and predacious fishes, such as $H$. fossilis and Mystus tengara $\left(3.32 \times 10^{6} / \mathrm{mm}^{3}\right.$ and 4.03 $\mathrm{x} 10^{6} / \mathrm{mm}^{3}$ ), whereas in the relatively slow and inactive Channa punctatus and Mastacemblus pancalus these values are comparatively low $\left(2.74 \times 10^{6} \mathrm{~mm}^{3}\right.$ and 2.93 x $10^{6} \mathrm{~mm}^{3}$ ) which supported our study. The RBC levels were highest in Catla catla $\left(2.9 \times 10^{6} / \mathrm{mm}^{3}\right)$ followed by L.rohita and C.striatus and lowest in C.carpio $\left(0.77 \times 106 / \mathrm{mm}^{3}\right)$ by Kandeepan (2014). In the present study, lower values of RBC count were observed in cypriniformes consisting of L. rohita and C. carpio. Although $\mathrm{RBC}$ count was higher in first group, $\mathrm{Hb}$ values were higher in $2^{\text {nd }}$ group consisting of $A$. testudineus and $C$. striatus. Reduction in the quantity of food and stress may induce macrocytic 
anemia in these species. In this condition, $\mathrm{RBC}$ decreases and they become abnormally large (macrocytes) and the quantity of $\mathrm{Hb}$ increases.

The fishes of the 2 nd group can move from pond to pond thus they must have to take more oxygen from water and atmosphere. This may be another reason for the increased value of hemoglobin, which is the respiratory pigment. Since $A$. testudineus and $C$. striatus are adapted to breathe atmospheric air by virtue of their possessions of accessory respiratory organs, they can accommodate in a wide variety of habitat from swamps to oxidation ponds, which are deficient in dissolved oxygen. In fish blood, oxygen is carried in combination with hemoglobin and this is very important for the survival of the fish. According to Larsson et al. (1976) the lesser values of RBC and hemoglobin are observed in slow moving, sedentary and benthic species, whereas the active, predacious and pelagic species give comparatively higher erythrocyte and leukocyte counts, hemoglobin content, etc. Pandey et al., (1976) reported a great variation in RBC number and other blood components in different species of fish. Starmach (1970) relates the number of RBC and hemoglobin concentration to the oxygen content of the surrounding water.

In our study WBC was found to be increased in different groups of teleosts after 7 days in response to increase in production of leucocytes in the hematopoietic tissue of the kidney and perhaps the spleen. According to Douglass and Jane 2010, WBC levels have implications for immune responses and the ability of the animal to fight infection. Species with higher levels of WBC will be able to fight infection more effectively than other species. In the first group of teleosts consisting of $H$. fossilis and C. gariepinus, lymphocytes which produce antibodies, were found in greater numbers at the day of catch itself. This group of fishes with high body size and weight are not all sensitive to the changing environment as compared to other group of cultivable teleosts. The high percentage level of observed lymphocytes in these teleosts also suggest that they were not seriously stressed (Pickering, 1986). The primary consequence of the observed changes in leukocyte count in stressed fish is suppression of the immune system and increased susceptibility to disease. Limanda linianda showed an increase in WBC in laboratory conditions which was believed to be caused by migration of white blood cells from the spleen to the blood circulation (Puisford et al, 1994)

Baxhall and Daisely (1973) have reported the possibility of using haematocrit as a tool in aquaculture and fishery management for checking anemic condition. PCV was high in second group of teleosts consisting of $A$. testudineus and $C$. striatus. The formation of macrocytes explains this. As the size of RBC increases, its volume also increases by increasing the hematocrit value. The present study revealed that hemoglobin, MCV \& $\mathrm{MCHC}$ were also high in second group of teleosts consisting of A. testudineus and C. striatus. The increase in PCV value accounts for the MCV and MCHC value. Kandeepan (2014) reported that highest $\mathrm{Hb}$ and Hemotocrit (Hct) or PCV concentrations were observed in $C$. striatus followed by $C$. carpio and Catla catla, the lowest levels were recorded in L.rohita. In the present study, lowest $\mathrm{Hb}$ and PCV concentrations were reported in cypriniformes consisting of Labeo rohita and Cyprinus carpio. The mean cell hemoglobin $(\mathrm{MCH})$ was higher in $3^{\text {rd }}$ group of fishes consisting of L. rohita and $C$. carpio. Since both of them are cultivable fishes, habitat changes had affected them only to a lesser extent. The food given to them in the laboratory condition was of the same quantity and quality as given to them in the rearing period. This may be the reason for high value of their hemoglobin.

\section{Conclusion}

The present study revealed that acclimation to captivity induced changes in haematological parameters of few fresh water teleosts fishes. These variations observed in the haematological indices can be attributed to protective mechanism against stress occurred in acclimation period. The perturbations in these blood parameters were resulted from disturbances in hematopoietic system of teleosts fish in response to stress factors raised in acclimation period.

\section{REFERENCES}

Akinrotimi, O.A., Abu Omg., Ansa, E.J., Edun, O.M. and George O.S. (2009). Hematological responses of Tilapia guineensis to acute stress. Interl $J$ of Natl and Appl Sci, 5 (4): 338-343.

Banerjee, V. (1957). Morphology and coagulation time of blood cell on Heteropneustes fossilis (Bloch). Curr Sci, $26-59$

Blaxhall, P.C. and Daisley, K.W. (1973). Routine haematological methods for use with fish blood. J. Fish Biol, 5: 771 - 781 .

Das B.C. (1965). Age-related trends in the blood chemistry and haematology of the Indian carp (Catla catla). Gerontologia, 10: 47 - 64.

Douglass J.W. and Jane K.W. (2010). Schalm s Veterinary Hematology. John Wiley and Sons (eds.), Blackwell Publishing Ltd. pp.1232

Gabriel, U.U., Anyanwu, P.E. and Akinrotimi AO. (2007a). Blood characteristics associated with confinement stress in black chin tilapia. Sarotherodon melanotheron. J Fish Intl, 2(2): 186-189.

Gardner, G.R. and Yevich, P.P. (1970). Histological and haematological response of an estuarine teleost to cadmium. $J$ of Fisheries Res Board of Canada, 27:2185 $-2196$.

Goel, K.A., Mishra, B.P., Gupta, K. and Wadhwa, S. (1984). A comparative haematological study of a few freshwater teleosts. Ind J fish,3: 108-112.

Graham, J.B. (1997). Air-breathing Fishes: Evolution, diversity, and adaptation. Academic Press,San Diego.

Graham, M.S., Haedrich, R.L. and Fletcher, G.L. (1985). Hematology of three deep-sea fishes: A refection of low metabolic rates. Comp. Biochem. Physiol. A, New York, v. 80, p. $79-84$. 
Hattingh, J. and Van Pletzen, A.J.J. (1974). The influence of capture and transportation on some blood parameter of freshwater fish. Comp. Brochem physcol, 49a: 607-609.

Hrubec, T.C., Smith, S.A. and Robertson, J.L. (2001). Age related in haematology and chemistry values of hybrid striped bass chrysops Morone saxatilis. Vet. Clin. Pathol, 30 (1), 8-15.

Kandeepan, C. (2014). Heamatological and biochemic parameters on few fresh water south indian Teleosts. Int. J. Curr. Microbiol. App. Sci, 3(9) 1015-1022

Larsson A., Johansson-Sjobeck, M.L. and Fange, R. (1976). Comparative study of some haematological and biochemical blood parameters in fishes from Skagerrak. Fish. Biol,9: 425-440

Omoregie, E. (1995). Changes in the haematology of the Nile Tilapia Orochronis niloticus under the effect of crude oil. Hydrobio., 40(4): 287-292.

Pandey, B.N., Pajjdey, P.K., Choubey, B.J. and Dattamunshl, J.S. (1976). Studies on blood components of an air breathing siluroid fish Heteropneustes fossilis in relation to body size. Folia Haematol. 103, 101-116.

Pickering, A.D. (1986). Changes in the blood cell composition of the brown trout, salmo trutta during the spawning season. Journal of Fish Biology, 29:335 -347

Puisford, A.L., Lemaire-gong, S., Tomlinson, M., Coiling wood, N. and Glynn, P.J. (1994). Effects of acute stress on the immune system of the Dab, Limanda. Comp. Biochem Physi, 109:129-139.
Rehulka, J. and Adamec, V. (2004). Red blood cell indice for Rainbow trout (Onchorhynchus mykiss) reared in cage and raceway culture. Acta Veterinaria BRNO, 73:105-114

Sampath, K., Velanimial, S., Kennedy, L.J. and James R. (1993). Haernatoiogical changes and their recovery in Oreochronzis mossanibicus as a function of exposure period and sub lelthal levels of Ekalus. Acta Hydrobiol, 35:73-83.

Starmach, J. (1970). The number of erythrocytes in blood of Cottus poecilopus Heckel AND Cottis gobio L. Acta Biol. Cracon. Ser. Zool. 13, 243-249.

Verma, S.R., Santa R. and Dalela, R.C. (1982). Indicators of stress induced by pesticides in Mystus vittatus Haematological Parames. Ind. J. Envron. Hith, 24 (1) $58-64$

Vosylien'e, M.Z. (1999). The effect of heavy metals on haematological indices of fish. Acta Zool. Litvanica Hydrobiol. 9 (2): 76-82.

Weber, R.E. and Wells, R.M.G. (1989). Hemoglobin structure and Function. In: Comparative Pulmonary Physiology: 279-310 (S.C. Wood, Ed.). Marcel Dekker, New York.

Wells R.M.G., Baldwins J., Seymour, R.S., Christian, K. and Brittain, T. (2005). Red blood cell function and haematology in two tropical freshwater fishes from Australia. Comp. Biochem. Physiol. A, New York, v. 141, p. 87-93.

Wintrobe, M..M. (1978). Clinical Haematology. H. Kimpton press London, UK. pp. 488. 